SIR-Keith Runcorn (19 September, p.196) has obviously cogitated carefully over the report of the Natural Environmental Research Council (NERC) committee chaired by me which reviewed methods of allocating research studentships, since his letter appeared nearly a year after the report was published. His views are reminiscent of some of the evidence we received from heads of departments (possibly a slight majority), but which were opposed by a majority of other members of staff and by virtually all the students themselves. Our conclusions were not entirely maverick; we advertised our review as widely as we could and had about 400 comments from academics, employers, students and other research councils about the most equitable and positive ways of allocating studentships. Our recommendations were based on assessing all the information we had, giving appropriate weight to the relevance of the suggestions and criticisms.

It is of little general interest to respond to all the misapprehensions accumulated by Professor Runcorn. Perhaps the drafting of our report was obscure. But five points need making:

(1) The committee consisted of three Earth scientists, two former research council secretaries with backgrounds in the biological sciences (Sir John Gray of the Medical Research Council and Sir William Henderson of the then Agricultural Research Council, both of whom had overseen allocation procedures very different from that used by NERC), and myself, an ecological geneticist. We examined the past and present methods used by all five British research councils, and other possibilities suggested by our respondents. We were unanimous in our recommendations, and our report was endorsed by the NERC Council.

(2) Professor Runcorn opines that "the ratio of geophysical to geological studentships is too small both for scientific advance and for national needs". This is an appropriate and fashionable prejudice for a geophysicist to hold. The underlying problem is that it is extremely difficult to determine the proper allocation of studentships between disciplines. If demand is any guidance, requests in the NERC area for life science studentships are much greater than for Earth science ones. My committee recommended an "in-depth independent study with a view to laying down guidelines for the distribution of available awards between the (subject) committees", and this has been accepted by the NERC Council.

The general and very important problem of forecasting "national need" was analysed by a White Paper on Postgraduate Education (Cmnd 6611, 1976) which expressed the view that "it is unlikely that a close match between supply and demand could ever be achieved and it will be important to resist the temptation to forecast and plan with spurious precision". Sir Peter Swinnerton-Dyer's ABRC Working Party (1983) reviewed past endeavours on the subject and concluded that all these "attempts at manpower planning (for the supply of scientists and technologists) foundered principally on an uncritical faith in the economic contribution of education and on a confused concept of demand. . . since there are many $\mathrm{PhDs}$ whose working career has borne little relation to the subject of their thesis however potent the contribution of research training has been to their intellectual and practical development. It remains a truism that the quality of highly trained manpower is as significant as its quantity."

(3) Professor Runcorn repeats the accusation raised originally by the heads of university zoology departments that membership of a NERC committee improves the chance of getting a studentship project approved. If true, this would be worrying. The fact is that some committee members are more successful than expected in some years and less successful in others. There is no consistent picture, but (as Professor Runcorn notes) NERC "Council takes a very serious view (of this). . . important area which will be carefully monitored in the future". There need be no mystery or suspicion here: if the most active and productive research workers constitute the grants committees, they would be expected to obtain a higher than average proportion of awards. Perhaps the key factor is that the grants committees are not self-perpetuating cabals: for some time NERC has been inviting university departments and individuals to nominate to the committees, and this invitation was repeated in the committee's report. For the record, five of the $18 \mathrm{mem}$ bers of NERC's current geological sciences training awards committee are geophysicists.

(4) Professor Runcorn wants NERC to abandon its "effortful, cumbersome, expensive and unsatisfactory scheme". Ignoring his fourth adjective, our published response to this comment was that "as each research studentship costs in excess of $£ 17,000$ and represents three very important years of a student's life, the expenditure of a supervisor's time (in preparing an application) is fully justified".

(5) However, I suspect that the crucial difference between Professor Runcorn and my committee is over the purpose of a research studentship. We firmly and explicitly rejected the idea that a PhD student should be primarily a research assistant involved in an ongoing research project. Professor Runcorn quotes disparagingly "NERC's statement of the primary objective of a research studentship". Our understanding and conclusions were based on two clear objectives. I am unrepentant about these:

"The primary aim of Council's policy must be to enable the intellectually most able graduates to receive the best possible training. An essential part of this training is the preparation of a $\mathrm{PhD}$ thesis. which also provides a means of ensuring that research undertaken is preserved and can be made available to others. Within the context of research training, it is council's aim to influence the quality of training and its direction and content.

"The second main objective of council's policy can be defined as ensuring that there is an adequate supply of manpower trained at postgraduate level to meet the national requirement in the sciences most closely concerned with the natural environment.

"A very important consequence of research training, even though incidental to that training, is the major contribution which research students make to the research output of universities. In itself, provision of training awards is a major contribution to the research community."

I am not clear why Professor Runcorn is so dismayed by our report. As a scientist. he cannot logically complain about an exercise that examines all relevant data and then excludes inadequate conclusions from it (even if he does not like the positive solutions that emerge). If it is any comfort to him, I was not allocated a NERC studentship this year, despite the fact that I put forward two excellent proposals to the grants committees.

Depatment of Zoology,

University College London,

London WCIE 6BT, UK

\section{Human life}

SiR-The distinction between dependently viable protoplasmic life and independently viable organismal life (respectively at the level scale of the molecule and of the individual), as made by R. C. Hoult (Nature 8 August, p.480), is quite correct, although it does not follow that the life quality necessarily attributable to a fetus in utero is that of protoplasmic life only.

The fetus has undoubtedly an organismal life, and we can speak of "fetal behavioural states" (Prenatal Diag. July 1985, p.269) in spite of its dependence on its mother for energy supply. An infant seems not to differ very much in this respect. It must be recalled that, up to the onset of implantation, the human conceptus is "free living" in the sense that it is not attached to the mother in any way. Nor can I see how a human adult individual during parenteral nutrition could lose his "human life" or organismal quality.

M. ZATTI

Universita degli Studi di Verona,

Centro Ospedaliero Clinicizzato, Istituto di Chimica e Microscopia, 37134 Verona, Italy 